\title{
No beneficial effects of vitamin D supplementation on muscle function or quality of life in primary hyperparathyroidism: results from a randomized controlled trial
}

\author{
Lars Rolighed' ', Lars Rejnmark², Tanja Sikjaer², Lene Heickendorff ${ }^{3}$, \\ Peter Vestergaard $^{2,4}$, Leif Mosekilde ${ }^{2}$ and Peer Christiansen ${ }^{1}$ \\ ${ }^{1}$ Breast and Endocrine Section, Department of Surgery $P$ and ${ }^{2}$ Department of Endocrinology and Internal Medicine, \\ Aarhus University Hospital, Tage Hansens Gade 2, 8000 Aarhus C, Denmark, ${ }^{3}$ Department of Clinical Biochemistry, \\ Aarhus University Hospital, NBG, Aarhus, Denmark and ${ }^{4}$ Department of Endocrinology and Clinical Institute, \\ Aalborg University Hospital, Aalborg, Denmark
}

Correspondence should be addressed to L Rolighed

Email

larsrolighed@gmail.com

\begin{abstract}
Context: Impairments of muscle function and strength in patients with primary hyperparathyroidism (PHPT) are rarely addressed, although decreased muscle function may contribute to increased fracture risk.

Objective: We aimed to assess the changes in muscle strength, muscle function, postural stability, quality of life (QoL), and well-being during treatment with vitamin D or placebo before and after parathyroidectomy (PTX) in PHPT patients. Design: A randomized placebo-controlled trial.

Patients: We included 46 PHPT patients, mean age 58 (range 29-77) years and 35 (76\%) were women.

Interventions: Daily treatment with $70 \mu \mathrm{g}(2800 \mathrm{IU})$ cholecalciferol or placebo for 52 weeks. Treatment was administered 26 weeks before PTX and continued for 26 weeks after PTX.

Main outcome measures: Changes in QoL and measures of muscle strength and function.

Results: Preoperatively, 25-hydroxyvitamin D (25OHD) increased significantly (50-94 nmol/l) compared with placebo (57-52 nmol/l). We did not measure any beneficial effects of supplementation with vitamin $D$ compared with placebo regarding well-being, QoL, postural stability, muscle strength, or function. In all patients, we measured marked improvements in QoL, well-being $(P<0.01)$, muscle strength in the knee flexion and extension $(P<0.001)$, and muscle function tests $(P<0.01)$ after surgical cure. Postural stability improved during standing with eyes closed $(P<0.05)$, but decreased with eyes open $(P<0.05)$.

Conclusions: Patients with PHPT and $250 \mathrm{HD}$ levels around $50 \mathrm{nmol} / /$ did not benefit from vitamin D supplementation concerning muscle strength, muscle function, postural stability, well-being, or QoL. Independent of preoperative
\end{abstract} $250 H D$ levels, PTX improved these parameters.

\section{Introduction}

The risk of fracture is increased in patients with primary hyperparathyroidism (PHPT) (1) and bone mineral density (BMD) is reduced compared with healthy controls (2). Muscle strength and quality of life (QoL) is also impaired in PHPT (3), which may contribute to increased fracture risk independently of BMD. Muscle function is a central topic of debate and focus in clinical research (4). Muscle strength and function are obviously necessary for basic locomotion and increasingly important for persistent mobility and independency with aging. Furthermore, muscles interact
(C) 2015 European Society of Endocrinology Printed in Great Britain
European Journal of

Endocrinology

(2015) 172, 609-617

Published by Bioscientifica Ltd. 
with bones in both direct and indirect ways (5), which highlights the importance of physical activity in the elderly and in patients at increased risk of fracture.

Several mechanisms of action may account for the impaired QoL and muscle function in PHPT, including the increased plasma levels of PTH $(6,7,8)$. PTH receptors are expressed by muscle tissue (7) and in the CNS (7). Moreover, increased plasma calcium $\left(\mathrm{Ca}^{2+}\right)$ in PHPT may also be part of the explanation, due to the wellcharacterized involvement of $\mathrm{Ca}^{2+}$ in muscle contractions (9). Finally, low plasma levels of vitamin D (25OHD) are known to affect muscle strength and function and low levels are more common in PHPT than in healthy controls $(10,11)$. The vitamin $\mathrm{D}$ receptor is expressed by muscle tissue (12) and treatment with vitamin D has been shown to improve muscle strength (13) and increase muscle fiber size (12) in patients with low 25OHD levels. However, previous studies were often lacking a control group, a randomization procedure, a blinding procedure, or a combination of these limitations.

The classical treatment of PHPT is by parathyroidectomy (PTX) with removal of pathologic parathyroid tissue. Several studies have suggested that this operation improves both QoL and muscle strength $(8,14,15,16)$. However, with the current change in clinical presentation to mild or asymptomatic PHPT, surgery may not always be necessary (17). A treatment option in these patients includes vitamin D supplementation (18). In this randomized controlled trial (RCT) (19), PHPT patients with low 25OHD levels were randomized to 26 weeks of treatment with vitamin D or placebo before PTX followed by 26 weeks of continuous treatment after surgery. We have previously shown that preoperative vitamin $\mathrm{D}$ supplementation safely increased $25 \mathrm{OHD}$ by $88 \%$, reduced PTH levels by $17 \%$, and improved BMD at the lumbar spine by $2.5 \%$ without observing changes in plasma or urinary calcium (19). The primary endpoint was a decrease in PTH preoperatively. We now also report data on the secondary endpoints muscle strength, muscle function, postural stability, and QoL.

\section{Subjects and methods}

\section{Participants and study design}

We only included PHPT patients with vitamin D insufficiency ( $25 \mathrm{OHD}<80 \mathrm{nmol} / \mathrm{l}$ ) and established mildto-moderate hypercalcemia (plasma $\mathrm{Ca}^{2+}<1.60 \mathrm{mmol} / \mathrm{l}$ ) (19). The study was an investigator-initiated double-blind, randomized, placebo-controlled, parallel-group trial comparing treatment with a daily oral supplement of $70 \mu \mathrm{g}$ (2800 IU) cholecalciferol (vitamin D3) or similar placebo for 1 year. The treatment was administered for 6 months before PTX (at week $26 \pm 4$ weeks) and continued for 6 months following PTX. The study was performed in accordance with the Declaration of Helsinki II and guidelines on Good Clinical Practice (GCP). The GCP Unit at Aarhus University Hospital monitored the study. The study was approved by the Danish Data Protection Agency, the Ethical Committee of Central Denmark Region (\#M20080011), and registered at ClinicalTrials. gov (\#NCT00674154).

\section{Muscle strength and function}

We assessed the maximal voluntary isometric muscle strength both at the upper- and lower extremities with an adjustable dynamometer chair as previously reported (3). The method is known to be highly reliable (reliability coefficients (rc) of 0.88-0.96) for both upper end lower extremities (20). Maximal strength was measured in Newton $(\mathrm{N})$ and maximal force production in $\mathrm{N} / \mathrm{s}$. We used two physical function tests to assess performance comparable to daily activities. The first test was the time for ten repeated chair stands (RCS) without the use of hands. Secondly, the Timed Up and Go test (TUG), i.e. time to stand up from a chair, walk $3 \mathrm{~m}$, and return to the chair. The RCS test has a high level of reliability $(\mathrm{rc}=0.84)$, whereas the TUG test has a moderate reliability $(\mathrm{rc}=0.57)(20)$. Both tests discriminate well between functional levels (20) and are easy to use in the daily clinic. The muscle strength and functional tests were performed at week 0 (baseline), 25 (preoperative), and 52 (postoperative).

\section{Postural stability}

We assessed postural stability with the use of a stadiometer as previously detailed (3). The stadiometer records length $(\mathrm{mm})$ and speed $(\mathrm{mm} / \mathrm{s})$ of the sway in medio-lateral and anterior-posterior direction. The data are presented as velocity moment $\left(\mathrm{VM}, \mathrm{mm}^{2} / \mathrm{s}\right)$, which is a product of total length of sway in both directions per second. The stadiometer has an acceptable reliability coefficient $(\mathrm{rc}=0.53)(20)$. We measured postural stability under four different settings: i) normal standing with eyes open; ii) normal standing with eyes closed; iii) semitandem, and iv) tandem standing. We adjusted the best result (lowest VM) for differences in body height to scaled velocity moment $(\mathrm{SVM})=\left(\mathrm{VM} /(\text { height in } \mathrm{cm})^{2}\right) \times 180^{2}$. 


\section{Biochemistry}

We used standard laboratory methods for the measurements of creatinine kinase (CK) and lactate dehydrogenase (LDH). We collected blood samples before testing muscle strength and function. Analyses of vitamin D metabolites, vitamin D-binding protein, PTH, bone markers, creatinine, albumin, alkaline phosphatase, and plasma and urinary levels of calcium and phosphate were analyzed using goldstandard methods and presented previously (19).

\section{Quality of life}

We used the Danish translation of Short Form questionnaire 36 version 2 (SF-36) and WHO-Five Well-Being Index survey (WHO-5) to assess QoL and well-being. The SF-36 questionnaire consists of 36 questions which are grouped into eight domains describing physical functioning (PF), role-physical (RP), bodily pain (BP), general health (GH), vitality (VT), social functioning (SF), role-emotional (RE), and mental health $(\mathrm{MH})$. Furthermore, a mental component summary (MCS) score and physical component summary (PCS) score can be calculated using norm-based values according to the user's manual. The questionnaire is well validated and widely used to describe QoL in PHPT patients $(3,14,15,21,22)$. The WHO-5 index of well-being consists of five questions and answers are scored from 0 to 5 . The score is multiplied by 4 and presented as a total percentage from 0 to 100. A well-being score below 50\% indicates depressive affection (sensitivity $89 \%$ and specificity $86 \%$ ), and a score below $28 \%$ suggests depression (23).

\section{Body composition}

Using dual-energy X-ray absorptiometry (DXA, Hologic Discovery, Hologic, Inc., Waltham, MA, USA), we assessed body composition by whole-body scan at week 0,25 , and 52 . As these scans were added to the protocol after initiation of the study, we only report measures from week 25 and 52. Assessments include total and subtotal body mass, lean body mass, and fat mass (g). We calculated BMI as body weight divided by the square of the height $\left(\mathrm{kg} / \mathrm{m}^{2}\right)$.

\section{Statistical analyses}

We analyzed all data with the intention-to-treat approach. We assessed differences between groups using the Student's $t$-test or Wilcoxon rank sum test as appropriate. Changes within groups were tested by paired $t$-test or Wilcoxon signed-rank test. For serial changes in biochemical values, we used ANOVAs for repeated measurements. The correlations between variables were tested by bivariate correlation analyses $(r)$. We present mean values with $95 \% \mathrm{CI}$, mean \pm S.D., or median with 25 and 75 percentiles (inter quartile range $(\mathrm{IQR}))$. The level of significance was at $2 P<0.05$. The power calculation was based on an estimate to identify a preoperative PTH reduction during vitamin D treatment as previously presented (19). Hence, we planned to include 50 PHPT patients. We used STATA 10.0 for all statistical analyses.

\section{Results}

\section{Subjects, PTH, and vitamin D}

The characteristics of 46 included patients are given in Table 1. Forty-two patients completed the preoperative 25 weeks of the study and 40 patients completed all 52 weeks of study. The treatment was well tolerated and with a high level of compliance (96\%). During the preoperative phase, 25OHD increased significantly $(50( \pm 20) \mathrm{nmol} / \mathrm{l}$ to 94 $( \pm 18) \mathrm{nmol} / \mathrm{l})$ compared with placebo group $(57( \pm 18)$ $\mathrm{nmol} / \mathrm{l}$ to $52( \pm 18) \mathrm{nmol} / \mathrm{l})$ and caused a PTH decrease by $17 \%(P=0.01$; absolute difference $2.4 \pm 1.2 \mathrm{pmol} / \mathrm{l})$ in the vitamin $D$ group. Plasma creatinine, and plasma or urinary calcium levels did not change significantly.

\section{Muscle strength}

Table 2 gives the results on muscle strength measurements. At baseline, muscle strength $(\mathrm{N})$ and muscle force production (N/s) did not differ between groups at any of the measured muscle groups. Compared with placebo, vitamin $\mathrm{D}$ treatment did not cause significant changes in hand grip strength or muscle strength at elbow extension/ flexion or knee extension/flexion before PTX (baseline to week 25) or following surgery (week 26-52). Neither did max force production differ between groups in response to treatment (data not shown). Furthermore, the correlations between 25OHD levels and muscle strength measurements were not significant at baseline or after interventions.

Table 2 also gives changes in muscle strength within the entire group of patients independent of treatment allocation. Muscle strength improved significantly at knee extension and flexion at $60^{\circ}$ before surgery, and all measures at the knee improved following PTX. Improvements were only borderline significant after PTX at hand grip $(P=0.07)$ and elbow flexion $(P=0.08)$. Similar to the findings on muscle strength, muscle force production at most muscle groups increased after PTX in the entire group of patients (data not shown). No significant 
Table 1 Baseline characteristics of included patients with primary hyperparathyroidism presented as mean values with range or $95 \% \mathrm{Cl}$ or number $(n)$ with percentage, as appropriate.

\begin{tabular}{|c|c|c|c|c|c|}
\hline & Reference range & All & Vitamin D & Placebo & $P$ value \\
\hline$n(\%)$ & & $46(100)$ & $23(50)$ & $23(50)$ & \\
\hline$n$ female $(\%)$ & & $35(76)$ & $16(70)$ & $19(83)$ & 0.22 \\
\hline \multicolumn{6}{|l|}{ Characteristics, mean (range) } \\
\hline Age (years) & & $59(30 ; 77)$ & $60(30 ; 77)$ & $58(31 ; 73)$ & 0.51 \\
\hline Height $(\mathrm{cm})$ & & $170(155 ; 204)$ & $170(157 ; 189)$ & $169(155 ; 204)$ & 0.41 \\
\hline Weight $(\mathrm{kg})$ & & $81(55 ; 121)$ & $77(55 ; 114)$ & $86(56 ; 121)$ & 0.11 \\
\hline \multicolumn{6}{|l|}{ Plasma, mean $(95 \% \mathrm{Cl})$} \\
\hline Calcium (mmol/l) & $1.18-1.32$ & $1.41(1.39 ; 1.43)$ & $1.40(1.37 ; 1.43)$ & $1.41(1.38 ; 1.44)$ & 0.74 \\
\hline PTH (pmol/l) & $1.6-6.9$ & $13.0(11.1 ; 15.0)$ & $13.6(11.3 ; 15.9)$ & $12.5(9.2 ; 15.7)$ & 0.55 \\
\hline 25-hydroxy vitamin $\mathrm{D}(\mathrm{nmol} / \mathrm{l})$ & $50-160$ & $54.0(47.9 ; 60.0)$ & $50.2(40.6 ; 59.8)$ & $57.0(49.3 ; 65.5)$ & 0.23 \\
\hline Creatinine $(\mu \mathrm{mol} / \mathrm{l})$ & $45-90$ & $69.1(65.3 ; 72.9)$ & $67.4(61.7 ; 73.0)$ & $70.7(65.2 ; 76.2)$ & 0.38 \\
\hline Phosphate $(\mathrm{mmol} / \mathrm{l})$ & $0.76-1.41$ & $0.77(0.72 ; 0.82)$ & $0.75(0.68 ; 0.82)$ & $0.78(0.71 ; 0.85)$ & 0.49 \\
\hline Alkaline phosphatase (U/I) & 35-105 & $84.6(77.1 ; 92.1)$ & $85.7(75.6 ; 95.8)$ & $83.6(71.8 ; 95.5)$ & 0.79 \\
\hline Albumin $(g / l)$ & $34-45$ & $44.2(43.2 ; 45.2)$ & $43.9(42.4 ; 45.4)$ & $44.4(42.9 ; 45.9)$ & 0.60 \\
\hline Creatinine kinase $(U / I)$ & $50-150$ & $92(73 ; 111)$ & $90(54 ; 125)$ & $94(77 ; 111)$ & 0.82 \\
\hline Lactate dehydrogenase (U/I) & $115-255$ & $173(161 ; 185)$ & $165(150 ; 180)$ & $181(163 ; 198)$ & 0.19 \\
\hline
\end{tabular}

The $P$ value indicates between group differences.

correlations were found between changes in plasma levels of $25 \mathrm{OHD}, \mathrm{PTH}$, or $\mathrm{Ca}^{2+}$ and changes in muscle strength.

\section{Muscle function}

Treatment with vitamin $\mathrm{D}$ did not cause significant changes in the TUG or the RCS test compared with placebo. In the entire group of patients, the RCS test improved significantly before PTX $(11 \%, P<0.001)$ as well as following surgery $(8 \%, P<0.001)$, whereas the TUG test only improved following surgery $(10 \%, P<0.01)$. The postoperative changes were not significantly correlated with changes in plasma levels of PTH, 25OHD, or $\mathrm{Ca}^{2+}$.

\section{Postural stability}

Measurement of postural stability showed no effects of vitamin D treatment compared with placebo (Table 3). Within the entire group of patients, SVM increased postoperatively (week 26-52) during normal standing with eyes open, whereas it decreased during normal standing with eyes closed. The balance results did not correlate significantly with $25 \mathrm{OHD}$ levels.

\section{Body composition}

Treatment with vitamin D did not affect body weight. In the entire group of patients, body weight increased by $1208 \mathrm{~g}$ $(P=0.004)$ from week 25 to week 52 , with no differences between groups $(P=0.59)$. This resulted in an increased BMI (from 28.7 to $\left.29.1 \mathrm{~kg} / \mathrm{m}^{2}\right)$ after PTX $(P=0.007)$ with no differences between groups ( $P=0.88$ ). The increased body weight was due to an equal increase in lean body mass (mean \pm s.D.: $597 \pm 1472 \mathrm{~g}$ ) and total fat mass (mean \pm s.D.: $581 \pm 1886 \mathrm{~g}$ ) with no difference between groups.

\section{QoL and well-being}

Figure 1 shows the percentage change in norm-based scores of QoL between time points of measurements as assessed by the SF-36 questionnaire for the eight subdomains and two component scores. Preoperatively, QoL scores improved in the placebo compared with the vitamin $\mathrm{D}$ group in the $\mathrm{RP}$ and GH domain causing an improved PCS, whereas indices of mental health (VT, SF, RE, MH, and MCS) did not change significantly between groups before PTX.

Postoperatively, changes in scores did not differ significantly between groups. For all patients, we found a significant postoperative improvement in six of eight domains. This caused an overall improvement in the MCS $(P=0.004)$, whereas the PCS only improved borderline significantly $(P=0.09)$.

The WHO-5 index of well-being and changes over time did not differ between groups. Postoperatively, there was an improvement in the entire group of patients from a median score of 64 (IQR: 44;80) to 76 (IQR: 54;82) $(P<0.01)$.

\section{CK and LDH}

As shown in Fig. 2, during the 52 weeks of study, vitamin D treatment did not affect plasma levels of CK (ANOVA $P=0.74$ ) or LDH (ANOVA $P=0.74$ ). 
Table 2 Muscle strength measurements for participants at baseline followed by percentage change in muscle strength before operation (week 0-25), after operation (week 26-52), and for the whole study period (week 0-52). Results are presented as median values and inter quartile range (IQR).

\begin{tabular}{|c|c|c|c|c|}
\hline \multirow[b]{2}{*}{ Muscle strength $(\mathrm{N})$} & \multirow[b]{2}{*}{ Week 0 (median (IQR)) } & \multicolumn{3}{|c|}{ Percentage change median (IQR) } \\
\hline & & Week 0-25 & Week 25-52 & Week 0-52 \\
\hline \multicolumn{5}{|l|}{ Hand grip } \\
\hline Placebo & $290(260 ; 382)$ & $-1.0(-5 ; 14)$ & $3.3(-10 ; 11)$ & $4.0(-5 ; 21)$ \\
\hline Vitamin D & $304(236 ; 414)$ & $2.2(-10 ; 10)$ & $5.5(-4 ; 20)$ & $4.0(-6 ; 17)$ \\
\hline All & $290(242 ; 382)$ & $-0.6(-6 ; 12)$ & $3.4(-8 ; 14)$ & $4.0(-6 ; 20)^{*}$ \\
\hline \multicolumn{5}{|l|}{ Elbow flexion } \\
\hline Placebo & $197(149 ; 222)$ & $2.7(-2.2 ; 7.7)$ & $2.0(-2.8 ; 6.7)$ & $4.6(-2.1 ; 11.3)$ \\
\hline Vitamin D & $171(147 ; 263)$ & $1.9(-5.0 ; 8.8)$ & $7.3(0.8 ; 13.7)^{*}$ & $8.6(0.8 ; 16.4)^{*}$ \\
\hline All & $179(147 ; 262)$ & $2.3(-1.8 ; 6.5)$ & $4.5(0.5 ; 8.6) *$ & $6.6(1.5 ; 11.7) *$ \\
\hline \multicolumn{5}{|l|}{ Elbow extension } \\
\hline Placebo & $123(96 ; 153)$ & $10.4(-1.1 ; 21.9)$ & $3.5(-4.9 ; 11.8)$ & $12.9(0.4 ; 25.4) *$ \\
\hline Vitamin D & $113(90 ; 202)$ & $0.8(-6.1 ; 7.7)$ & $5.0(-2.4 ; 12.5)$ & $5.7(-4.5 ; 15.8)$ \\
\hline All & $115(95 ; 154)$ & $5.6(-1.2 ; 12.4)$ & $4.2(-1.3 ; 9.8)$ & $9.3(1.3 ; 17.3)^{*}$ \\
\hline \multicolumn{5}{|l|}{ Knee extension $60^{\circ}$} \\
\hline Placebo & $319(278 ; 372)$ & $7.9(0.6 ; 15.1)^{*}$ & $14.6(6.7 ; 22.6)^{\dagger}$ & $23.1(12.4 ; 33.8)^{\ddagger}$ \\
\hline Vitamin D & $306(205 ; 418)$ & $6.4(-3.3 ; 16.0)$ & $13.4(3.3 ; 23.5)^{*}$ & $19.6(4.9 ; 34.2)^{*}$ \\
\hline All & $319(223 ; 418)$ & $7.1(1.1 ; 13.1)^{*}$ & $14.0(7.7 ; 20.4)^{\ddagger}$ & $21.4(12.7 ; 30.0)^{\ddagger}$ \\
\hline \multicolumn{5}{|l|}{ Knee extension $90^{\circ}$} \\
\hline Placebo & $349(301 ; 387)$ & $7.2(-0.4 ; 14.8)$ & $10.2(5.1 ; 15.3)^{\ddagger}$ & $18.2(9.1 ; 27.2)^{\ddagger}$ \\
\hline Vitamin D & 307 (204;444) & $2.9(-5.6 ; 11.5)$ & $10.7(2.7 ; 18.6)^{*}$ & $11.1(0.1 ; 22.1)^{*}$ \\
\hline All & $349(254 ; 414)$ & $5.1(-0.4 ; 10.6)$ & $10.4(5.8 ; 15.0)^{\ddagger}$ & $14.7(7.7 ; 21.8)^{\ddagger}$ \\
\hline \multicolumn{5}{|l|}{ Knee flexion $60^{\circ}$} \\
\hline Placebo & $134(99 ; 158)$ & $14.6(2.2 ; 26.9)^{*}$ & $11.4(4.0 ; 18.8)^{\dagger}$ & $25.1(8.4 ; 41.7)^{\dagger}$ \\
\hline Vitamin D & $130(86 ; 175)$ & $9.9(-2.7 ; 22.4)$ & $16.7(6.0 ; 27.3)^{\dagger}$ & $29.5(4.1 ; 54.9) *$ \\
\hline All & $132(91 ; 158)$ & $12.3(3.7 ; 20.9)^{\dagger}$ & $14.1(7.6 ; 20.6)^{\ddagger}$ & $27.3(12.2 ; 42.5)^{\ddagger}$ \\
\hline \multicolumn{5}{|l|}{ Knee flexion $90^{\circ}$} \\
\hline Placebo & $128(103 ; 140)$ & $12.3(1.6 ; 23.0)$ * & $16.7(6.1 ; 27.3)^{\dagger}$ & $31.612 .3 ; 50.8)^{\dagger}$ \\
\hline Vitamin D & $132(92 ; 194)$ & $5.4(-8.6 ; 19.4)$ & $28.8(12.5 ; 45.2)^{\dagger}$ & $32.8(9.4 ; 56.2)^{\dagger}$ \\
\hline All & $128(93 ; 168)$ & $8.9(0.1 ; 17.7)^{\star}$ & $22.8(12.9 ; 32.6)^{\ddagger}$ & $32.2(17.2 ; 47.2)^{\ddagger}$ \\
\hline
\end{tabular}

Significant results between groups: none. Significant results within groups: ${ }^{*} P<0.05,{ }^{\dagger} P<0.01,{ }^{\ddagger} P<0.001$.

Assessment of effects of PTX in the entire group of patients (independent of treatment allocation) showed an increase in CK levels from a median of 78 (IQR: 50;109) to 86 (IQR: $69 ; 125) \mathrm{U} / 1$ during the 52 weeks of follow-up $(P<0.01)$. Before surgery, CK levels did not change, whereas CK levels increased by $14 \%$ (IQR: 0;47\%) following surgery $(P<0.01)$. Similarly, LDH levels increased by $12 \%$ (CI: $8 ; 17 \%, P<0.001$ ) from 171 (CI: $159 ; 183$ ) to 191 (CI: 178;203) $\mathrm{U} / \mathrm{l}$ in the entire group of patients during the 52 weeks of follow-up. The levels did not change before PTX, but increased postoperatively by $11 \%$ (CI: 7;16\%, $P<0.001$ ).

\section{Discussion}

Muscle function and strength are known to be impaired in PHPT (3). As low vitamin D levels are often encountered in patients with PHPT and are known to exert adverse effects on muscle performance, we investigated whether low vitamin D levels may be an explanation for a reduced muscle function in PHPT. However, in our RCT, the baseline 25OHD levels were around $50 \mathrm{nmol} / \mathrm{l}$ and patients did not benefit from preoperative vitamin $\mathrm{D}$ supplementation with regard to muscle function. Neither did the treatment improve QoL, well-being, or postural stability. However, muscle strength, muscle function, well-being, and QoL improved significantly following PTX, suggesting that physical and neurophysiological impairments in patients with PHPT are not attributable to low vitamin D levels but rather to the disease itself.

Our findings of a preoperative increased QoL score in the RP and GH domains resulting in an improved MCS score in the placebo group compared with the vitamin D group were against our a priori expectation of beneficial effects of vitamin D. In groups of patients without PHPT, low plasma 25OHD have also been associated with reduced QoL (24), and an RCT suggested improved QoL after vitamin D repletion (25). It is well known that PHPT is associated with a reduced QoL as measured by SF-36 
Table 3 Measurements of postural stability for all included participants at baseline followed by percentage change in scaled velocity moment before operation (week 0-25), after operation (week 26-52), and for the whole study period (week 0-52). Results are presented as median values and inter quartile range (IQR).

\begin{tabular}{|c|c|c|c|c|}
\hline \multirow[b]{2}{*}{ Scaled velocity moment $\left(\mathrm{m}^{2} / \mathrm{s}\right)$} & \multirow{2}{*}{$\begin{array}{c}\text { Baseline } \\
\text { median (IQR) }\end{array}$} & \multicolumn{3}{|c|}{ Percentage change median (IQR) } \\
\hline & & Week 0-25 & Week 26-52 & Week 0-52 \\
\hline \multicolumn{5}{|l|}{ Normal standing eyes open } \\
\hline Placebo & $5.7(3.4 ; 7.3)$ & $-11(-33 ; 19)$ & $20(-24 ; 46)$ & $16(-31 ; 56)$ \\
\hline Vitamin D & $4.6(3.1 ; 9.8)$ & $12(-20 ; 52)$ & $2.3(-14 ; 46)$ & $5.0(-20 ; 66)$ \\
\hline All & $4.8(3.3 ; 7.5)$ & $-7.4(-29 ; 42)$ & $15(-14 ; 46)^{*}$ & $8.8(-28 ; 62)$ \\
\hline \multicolumn{5}{|l|}{ Normal standing eyes closed } \\
\hline Placebo & $11(7 ; 15)$ & $-10(-35 ; 67)$ & $-13(-37 ; 16)$ & $-18(-44 ; 14)$ \\
\hline Vitamin D & $12(8 ; 23)$ & $11(-19 ; 74)$ & $-22(-32 ; 3)^{*}$ & $-9.6(-34 ; 68)$ \\
\hline All & $11(8 ; 22)$ & $3.0(-26 ; 67)$ & $-18(-37 ; 10) *$ & $-15(36 ; 24)$ \\
\hline \multicolumn{5}{|l|}{ Semi-tandem } \\
\hline Placebo & $28(23 ; 36)$ & $19(-30 ; 78)$ & $-17(-31 ; 15)$ & $-8.6(-40 ; 49)$ \\
\hline Vitamin D & $30(19 ; 41)$ & $25(-8 ; 71) *$ & $-20(-44 ; 21)$ & $-1.8(-14 ; 16)$ \\
\hline All & $29(22 ; 36)$ & $23(-25 ; 78)^{*}$ & $-18(-39 ; 18)$ & $-2.4(-30 ; 27)$ \\
\hline \multicolumn{5}{|l|}{ Tandem } \\
\hline Placebo & $60(46 ; 72)$ & $-25(-45 ; 9)$ & $12(-7 ; 49)$ & $-23(-36 ; 16)$ \\
\hline Vitamin D & $53(32 ; 92)$ & $9.8(-25 ; 35)$ & $-8.0(-30 ; 44)$ & $3.4(-21 ; 25)$ \\
\hline All & $60(42 ; 76)$ & $0.3(-33 ; 23)$ & $3.9(-25 ; 46)$ & $-9.2(-33 ; 19)$ \\
\hline
\end{tabular}

Significant results between groups: none. Significant results within groups: ${ }^{\star} P<0.05$.

$(3,15,22)$ or disease-specific symptom scores (16). This questionnaire was, however, not translated and validated in Danish, but results seem to correlate with SF-36 (26). Several mechanisms have been proposed as explanations for a reduced QoL in patients with PHPT. Elevated plasma $\mathrm{Ca}^{2+}$ levels have been associated with depression scores and $\mathrm{MH}$ scores in PHPT (27), and may exert negative effects on neuronal function and synaptic plasticity (28). Moreover, receptors for PTH are expressed in central nervous tissues (7) and high PTH levels may adversely affect psychological and cognitive functions (6), as well as elevated PTH and $\mathrm{Ca}^{2+}$ levels may cause cerebral hypoperfusion (29). However, as treatment with vitamin D in our study caused a $17 \%$ decrease in PTH levels without affecting plasma $\mathrm{Ca}^{2+}$ levels (19), such mechanisms of action do not seem to provide an appropriate explanation for our findings. Moreover, it may be questioned whether slightly elevated levels of $\mathrm{Ca}^{2+}$ and PTH actually affects QoL, as QoL does not seem to be impaired in mild hyperparathyroid hypercalcemia caused by familiar hypocalciuric hypercalcemia (30). Further studies are needed to evaluate the effect of vitamin D supplementation on QoL in patients with PHPT including disease-specific questionnaires.

The increased risk of fracture in PHPT patients may be due to one or more of the following: low BMD, decreased muscle strength, decreased muscle function, and impaired postural stability (3). Hence, we applied a number of tests which have been shown to predict risk of falls and fractures. The RCS has been associated with risk of hip fractures (31) and the TUG test has been associated with the risk of falling (32). Moreover, postural sway and strength at knee extension/flexion has been associated with risk of falling $(32,33)$. Importantly, treatment of low vitamin D levels improves bodily sway, number of falls, and TUG in RCTs $(34,35)$. Despite studying a population of PHPT patients with vitamin D insufficiency, our intervention with a daily high dose of vitamin $\mathrm{D}$ did not improve physical performance compared with placebo. Neither did our intervention affect lean tissue mass or biochemical markers of muscle tissue, suggesting that the physical impairment in PHPT is not due to low vitamin D levels when baseline 25OHD levels are around $50 \mathrm{nmol} / \mathrm{l}$.

Despite no beneficial effect of the intervention with vitamin $\mathrm{D}$ on measured indices, our study does suggest positive effects of PTX on QoL and muscle function, which is in accordance with the findings from several previous observational studies $(16,27)$. Accordingly, we found that PTX was associated with a better WHO-5 index of wellbeing and an improvement in six of eight subdomains of the SF-36 questionnaire. Moreover, muscle strength increased and results of RCS and TUG improved. Our findings of increased CK and LDH levels may be caused by increased physical activity following PTX. Biochemical levels of CK are considered as a quantitative marker of muscle tissue and may reflect skeletal muscle micro 

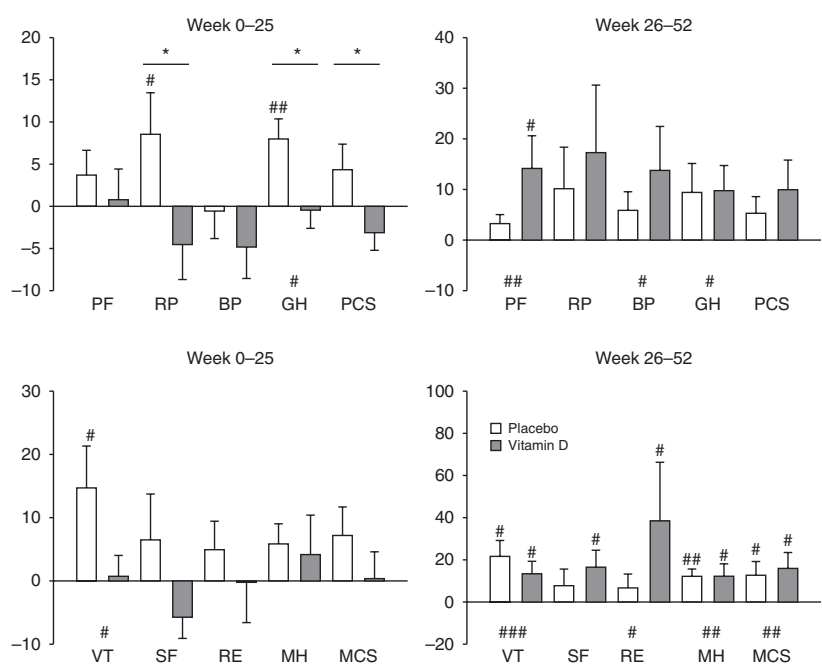

\section{Figure 1}

Percentage changes in quality-of-life measurements. Data are presented as mean and S.E.M. for each of the eight subdomains and two summary scores; physical function (PF), role physical $(\mathrm{RP})$, bodily pain (BP), general health $(\mathrm{GH})$, vitality $(\mathrm{VT})$, social function (SF), role emotional (RE), mental health $(\mathrm{MH})$, physical component summary (PCS), and mental component summary (MCS). * $P<0.05$ between groups, ${ }^{\#} P<0.05$ within groups, \#\# $P<0.01$ within groups, ${ }^{\# \# \#} P<0.001$ within groups.

trauma (36). CK is known to increase and peak 1-4 days after different types of exercise and may remain elevated for several days (37). The resting values of CK are therefore also elevated in physically active individuals compared with non-active controls (38). The small but significant increases in $\mathrm{CK}$ and $\mathrm{LDH}$ in this study may consequently be a result of increasing physical activity after PTX. Effects of PTH on muscle tissue have previously been studied by Reppe et al. (7), showing a marked dysregulation of muscle gene expression in patients with PHPT, which was especially pronounced for genes regulating proteins involved in the contractile process. Hence, the authors report PTH-induced upregulation in 46 of 50 relevant genes which may lead to a state of local energy insufficiency due to marked increased activity (7). Muscle-specific energy insufficiency might explain the muscle weakness in PHPT and the improvements seen after PTX. If so, the preoperative decrease in PTH levels in response to vitamin $\mathrm{D}$ supplementation as observed in our study may not be large enough to exert such beneficial effects.

The major strength of our study is the randomized, placebo-controlled, double-blind design. We used well validated questionnaires, tests, assays, and other equipment to assess effects. However, the strength of the study is limited by the relatively small number of participants. With 40 patients completing the study, we cannot exclude that a statistical type II error may apply to our findings. Also, a statistical type I error could explain the preoperative improvement of QoL in the placebo group. Although we aimed to include patients with vitamin D insufficiency, we cannot exclude that the mean baseline 250HD level of
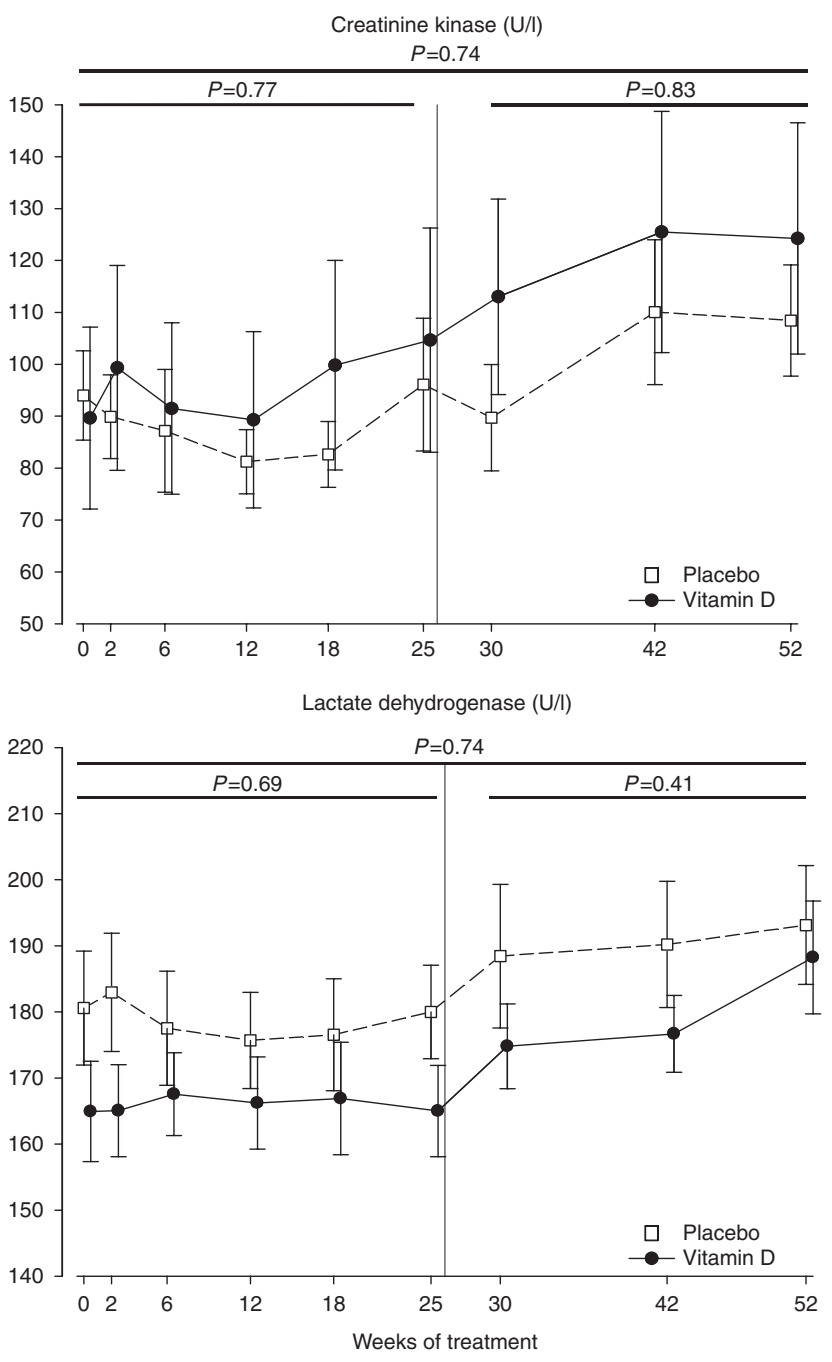

\section{Figure 2}

Presentation of mean values of creatinine kinase and lactate dehydrogenase for the two groups during the 52-week study. The vertical line indicates the time of parathyroidectomy at week 26 . The $P$ values are measured by ANOVA for repeated measurements and inserted for the preoperative period (week 0-25), the postoperative period (week 26-52), and the whole study period (week 0-52). 
$54 \mathrm{nmol} / \mathrm{l}$ was too high, the sample size too small, or the treatment duration too short to detect beneficial effects of preoperative vitamin D supplementation. In studies with very low baseline 25OHD values, muscle strength and muscle fiber size have been shown to increase after vitamin D supplementation $(12,13)$. Furthermore, the physical tests applied may be subject to a learning effect, i.e., participants may perform better at follow-up measurements as they have learnt how to perform the test at baseline. Furthermore, our data on effect of PTX on measured indices should be interpreted cautiously, as they are purely observational data. Only few results are available from RCTs on the effects of PTX, showing discrepant results. PHPT patients randomized to PTX in a RCT improved in functional capacity and sleepiness following surgical cure $(39,40)$. From other RCTs, QoL seem to improve, if the PHPT patients are symptomatic at baseline, whereas QoL did not improve in asymptomatic PHPT patients randomized to PTX $(14,15,22)$.

In conclusion, patients with PHPT and mean 25OHD levels around $50 \mathrm{nmol} / \mathrm{l}$ did not benefit from a further increase in plasma $25 \mathrm{OHD}$ levels in response to vitamin $\mathrm{D}$ supplementation concerning muscle strength, muscle function, postural stability, or QoL. Independent of preoperative vitamin D levels, PTX improved these parameters, suggesting that functional impairments seen in PHPT are caused by PTH or calcium elevations.

\section{Declaration of interest}

The authors declare that there is no conflict of interest that could be perceived as prejudicing the impartiality of the research reported.

\section{Funding}

This work was supported by the Hoerslev Foundation.

\section{References}

1 Vestergaard P, Mollerup CL, Frokjaer VG, Christiansen P, BlichertToft M \& Mosekilde L. Cohort study of risk of fracture before and after surgery for primary hyperparathyroidism. BMJ 2000321 598-602. (doi:10.1136/bmj.321.7261.598)

2 Christiansen P, Steiniche T, Brixen K, Hessov I, Melsen F, Charles P \& Mosekilde L. Primary hyperparathyroidism: biochemical markers and bone mineral density at multiple skeletal sites in Danish patients. Bone 199721 93-99. (doi:10.1016/S8756-3282(97)00078-1)

3 Rolighed L, Amstrup AK, Jakobsen NF, Sikjaer T, Mosekilde L, Christiansen P \& Rejnmark L. Muscle function is impaired in patients with "asymptomatic" primary hyperparathyroidism. World Journal of Surgery 201438 549-557. (doi:10.1007/s00268-013-2273-5)
4 Gallagher JC. Vitamin D deficiency and muscle strength: are they related? Journal of Clinical Endocrinology and Metabolism 2012974366 4369. (doi:10.1210/jc.2012-3720)

5 Karasik D \& Kiel DP. Evidence for pleiotropic factors in genetics of the musculoskeletal system. Bone 201046 1226-1237. (doi:10.1016/j.bone. 2010.01.382)

6 Jorde R, Waterloo K, Saleh F, Haug E \& Svartberg J. Neuropsychological function in relation to serum parathyroid hormone and serum 25-hydroxyvitamin D levels. The Tromso study. Journal of Neurology 2006253 464-470. (doi:10.1007/s00415-005-0027-5)

7 Reppe S, Stilgren L, Abrahamsen B, Olstad OK, Cero F, Brixen K, Nissen-Meyer LS \& Gautvik KM. Abnormal muscle and hematopoietic gene expression may be important for clinical morbidity in primary hyperparathyroidism. American Journal of Physiology. Endocrinology and Metabolism 2007292 E1465-E1473. (doi:10.1152/ajpendo.00487.2006)

8 Deutch SR, Jensen MB, Christiansen PM \& Hessov I. Muscular performance and fatigue in primary hyperparathyroidism. World Journal of Surgery 200024 102-107. (doi:10.1007/s002689910019)

9 Smith LR, Meyer G \& Lieber RL. Systems analysis of biological networks in skeletal muscle function. Wiley Interdisciplinary Reviews. Systems Biology and Medicine 20135 55-71. (doi:10.1002/wsbm.1197)

10 Bischoff-Ferrari HA, Dietrich T, Orav EJ, Hu FB, Zhang Y, Karlson EW \& Dawson-Hughes B. Higher 25-hydroxyvitamin D concentrations are associated with better lower-extremity function in both active and inactive persons aged $>$ or $=60 \mathrm{y}$. American Journal of Clinical Nutrition $200480752-758$.

11 Moosgaard B, Vestergaard P, Heickendorff L, Melsen F, Christiansen P \& Mosekilde L. Vitamin D status, seasonal variations, parathyroid adenoma weight and bone mineral density in primary hyperparathyroidism. Clinical Endocrinology 200563 506-513. (doi:10.1111/ j.1365-2265.2005.02371.x)

12 Ceglia L, Niramitmahapanya S, Morais MD, Rivas DA, Harris SS, Bischoff-Ferrari H, Fielding RA \& Dawson-Hughes B. A randomized study on the effect of vitamin D3 supplementation on skeletal muscle morphology and vitamin D receptor concentration in older women. Journal of Clinical Endocrinology and Metabolism 201398 E1927-E1935. (doi:10.1210/jc.2013-2820)

13 Glerup H, Mikkelsen K, Poulsen L, Hass E, Overbeck S, Andersen H, Charles P \& Eriksen EF. Hypovitaminosis D myopathy without biochemical signs of osteomalacic bone involvement. Calcified Tissue International 200066 419-424. (doi:10.1007/s002230010085)

14 Bollerslev J, Jansson S, Mollerup CL, Nordenstrom J, Lundgren E, Torring O, Varhaug JE, Baranowski M, Aanderud S, Franco C et al. Medical observation, compared with parathyroidectomy, for asymptomatic primary hyperparathyroidism: a prospective, randomized trial. Journal of Clinical Endocrinology and Metabolism 200792 1687-1692. (doi:10.1210/jc.2006-1836)

15 Rao DS, Phillips ER, Divine GW \& Talpos GB. Randomized controlled clinical trial of surgery versus no surgery in patients with mild asymptomatic primary hyperparathyroidism. Journal of Clinical Endocrinology and Metabolism 200489 5415-5422. (doi:10.1210/ jc.2004-0028)

16 Pasieka JL, Parsons LL, Demeure MJ, Wilson S, Malycha P, Jones J \& Krzywda B. Patient-based surgical outcome tool demonstrating alleviation of symptoms following parathyroidectomy in patients with primary hyperparathyroidism. World Journal of Surgery 200226 942-949. (doi:10.1007/s00268-002-6623-y)

17 Bilezikian JP, Brandi ML, Eastell R, Silverberg SJ, Udelsman R, Marcocci C \& Potts JT Jr. Guidelines for the management of asymptomatic primary hyperparathyroidism: summary statement from the Fourth International Workshop. Journal of Clinical Endocrinology and Metabolism 201499 3561-3569. (doi:10.1210/jc.2014-1413)

18 Khan AA. Medical management of primary hyperparathyroidism. Journal of Clinical Densitometry 201316 60-63. (doi:10.1016/j.jocd. 2012.11.010) 
19 Rolighed L, Rejnmark L, Sikjaer T, Heickendorff L, Vestergaard P, Mosekilde L \& Christiansen P. Vitamin D treatment in primary hyperparathyroidism: a randomized placebo controlled trial. Journal of Clinical Endocrinology and Metabolism 201499 1072-1080. (doi:10.1210/ jc.2013-4206)

20 Curb JD, Ceria-Ulep CD, Rodriguez BL, Grove J, Guralnik J, Willcox BJ, Donlon TA, Masaki KH \& Chen R. Performance-based measures of physical function for high-function populations. Journal of the American Geriatrics Society 200654 737-742. (doi:10.1111/j.1532-5415.2006.00700.x)

21 Amstrup AK, Rejnmark L \& Mosekilde L. Patients with surgically cured primary hyperparathyroidism have a reduced quality of life compared with population-based healthy sex-, age-, and season-matched controls. European Journal of Endocrinology 2011165 753-760. (doi:10.1530/EJE-11-0301)

22 Ambrogini E, Cetani F, Cianferotti L, Vignali E, Banti C, Viccica G, Oppo A, Miccoli P, Berti P, Bilezikian JP et al. Surgery or surveillance for mild asymptomatic primary hyperparathyroidism: a prospective, randomized clinical trial. Journal of Clinical Endocrinology and Metabolism 200792 3114-3121. (doi:10.1210/jc.2007-0219)

23 de Wit M, Pouwer F, Gemke RJ, Delemarre-van de Waal HA \& Snoek FJ. Validation of the WHO-5 well-being index in adolescents with type 1 diabetes. Diabetes Care 200730 2003-2006. (doi:10.2337/dc07-0447)

24 Ecemis GC \& Atmaca A. Quality of life is impaired not only in vitamin D deficient but also in vitamin D-insufficient pre-menopausal women. Journal of Endocrinological Investigation 201336 622-627. (doi:10.3275/8898)

25 Sakalli H, Arslan D \& Yucel AE. The effect of oral and parenteral vitamin D supplementation in the elderly: a prospective, doubleblinded, randomized, placebo-controlled study. Rheumatology International 201232 2279-2283. (doi:10.1007/s00296-011-1943-6)

26 Mihai R \& Sadler GP. Pasieka's parathyroid symptoms scores correlate with SF-36 scores in patients undergoing surgery for primary hyperparathyroidism. World Journal of Surgery 200832 807-814. (doi:10.1007/s00268-008-9509-9)

27 Weber T, Eberle J, Messelhauser U, Schiffmann L, Nies C, Schabram J, Zielke A, Holzer K, Rottler E, Henne-Bruns D et al. Parathyroidectomy, elevated depression scores, and suicidal ideation in patients with primary hyperparathyroidism: results of a prospective multicenter study. JAMA Surgery 2013148 109-115. (doi:10.1001/2013.jamasurg.316)

28 Iacovelli E, Gilio F, Mascia ML, Scillitani A, Romagnoli E, Pichiorri F, Fucile S, Minisola S \& Inghilleri M. Acute and chronic effects of hypercalcaemia on cortical excitability as studied by $5 \mathrm{hz}$ repetitive transcranial magnetic stimulation. Journal of Physiology 2011589 1619-1626. (doi:10.1113/jphysiol.2010.201111)

29 Cermik TF, Kaya M, Ugur-Altun B, Bedel D, Berkarda S \& Yigitbasi ON. Regional cerebral blood flow abnormalities in patients with primary hyperparathyroidism. Neuroradiology 200749 379-385. (doi:10.1007/ s00234-006-0198-5)

30 Jakobsen NF, Rolighed L, Nissen PH, Mosekilde L \& Rejnmark L. Muscle function and quality of life is not impaired in familial hypocalciuric hypercalcemia (FHH): a cross-sectional study on physiological effects of inactivating variants in the calcium sensing receptor gene (CaSR). European Journal of Endocrinology 2013169 349-357. (doi:10.1530/ EJE-13-0224)

31 Cawthon PM, Fullman RL, Marshall L, Mackey DC, Fink HA, Cauley JA, Cummings SR, Orwoll ES, Ensrud KE \& Osteoporotic Fractures in Men (MrOS) Research Group. Physical performance and risk of hip fractures in older men. Journal of Bone and Mineral Research 200823 1037-1044. (doi:10.1359/jbmr.080227)

32 Stel VS, Smit JH, Pluijm SM \& Lips P. Balance and mobility performance as treatable risk factors for recurrent falling in older persons. Journal of Clinical Epidemiology 200356 659-668. (doi:10.1016/S0895-4356 (03)00082-9)

33 Yau DT, Chung RC \& Pang MY. Knee muscle strength and visual acuity are the most important modifiable predictors of falls in patients after hip fracture surgery: a prospective study. Calcified Tissue International 201392 287-295. (doi:10.1007/s00223-012-9681-7)

34 Pfeifer M, Begerow B, Minne HW, Suppan K, Fahrleitner-Pammer A \& Dobnig H. Effects of a long-term vitamin D and calcium supplementation on falls and parameters of muscle function in communitydwelling older individuals. Osteoporosis International 200920 315-322. (doi:10.1007/s00198-008-0662-7)

35 Bischoff HA, Stahelin HB, Dick W, Akos R, Knecht M, Salis C, Nebiker M, Theiler R, Pfeifer M, Begerow B et al. Effects of vitamin D and calcium supplementation on falls: a randomized controlled trial. Journal of Bone and Mineral Research 200318 343-351. (doi:10.1359/ jbmr.2003.18.2.343)

36 Clarkson PM \& Hubal MJ. Exercise-induced muscle damage in humans. American Journal of Physical Medicine \& Rehabilitation 200281 (11 Suppl) S52-S69. (doi:10.1097/00002060-200211001-00007)

37 Mougios V. Reference intervals for serum creatine kinase in athletes. British Journal of Sports Medicine 200741 674-678. (doi:10.1136/bjsm. 2006.034041)

38 Nikolaidis MG, Protosygellou MD, Petridou A, Tsalis G, Tsigilis N \& Mougios V. Hematologic and biochemical profile of juvenile and adult athletes of both sexes: implications for clinical evaluation. International Journal of Sports Medicine 200324 506-511. (doi:10.1055/ s-2003-38198)

39 Perrier ND, Balachandran D, Wefel JS, Jimenez C, Busaidy N, Morris GS, Dong W, Jackson E, Weaver S, Gantela S et al. Prospective, randomized, controlled trial of parathyroidectomy versus observation in patients with "asymptomatic" primary hyperparathyroidism. Surgery 2009146 1116-1122. (doi:10.1016/j.surg.2009.09.034)

40 Morris GS, Grubbs EG, Hearon CM, Gantela S, Lee JE, Evans DB, Holmes HM, Busaidy NL, Jimenez C \& Perrier ND. Parathyroidectomy improves functional capacity in "asymptomatic" older patients with primary hyperparathyroidism: a randomized control trial. Annals of Surgery 2010251 832-837. (doi:10.1097/SLA. Ob013e3181d76bb3)

Received 3 November 2014

Revised version received 6 January 2015

Accepted 2 February 2015 